\title{
INTERRELATIONS BETWEEN GROWTH DIFFERENTIATION FACTOR 15, P-SELECTIN AND GALECTIN-3 AND CLINICAL COURSE IN PATIENTS WITH ARTERIAL HYPERTENSION AND TYPE 2 DIABETES MELLITUS
}

\author{
Anton Bilchenko \\ Department of Internal Medicine No. 1 \\ Kharkiv National Medical University \\ 4 Nauky ave., Kharkiv, Ukraine, 61022 \\ wallan106@gmail.com \\ Katerina Vysotska \\ Department of Propaedeutics of Internal Medicine and Physical Rehabilitation \\ V. N. Karazin Kharkiv National University \\ 4 Svobody sq., Kharkiv, Ukraine, 61022
}

\begin{abstract}
The aim of our study was to determine the base levels of Growth Differentiation Factor 15, P-selectin and Galectin-3 in blood plasma in patients with $\mathrm{AH}$ and T2DM and to assess their association with the diseases clinical course.

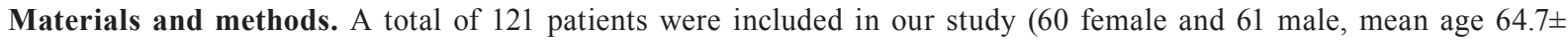
\pm 10.6 years, with $\mathrm{AH}$ and/or T2DM).

Patients were divided into three groups: 1st group with AH only (51 patient), 2nd group with AH and T2DM (57 patients) and 3rd group with T2DM only (13 patients, control group). GDF-15, Galectin-3 and P-selectin tests were performed using standard enzyme-linked immunosorbent assay kits (ELISA).

Results. Compared with AH without T2DM and T2DM only groups, AH with T2DM group had a statistically significant higher level of GDF-15. Grade 3 hypertension group had a significantly lower level of GDF-15 compared with Grade $1 \& 2$ hypertension groups. P-selectin mean level was significantly higher in Grade 3 hypertension group GDF-15 compared with Grade $1 \& 2$ hypertension groups. We observed weak correlation between Galectin-3 and GDF-15 in blood plasma, which was confirmed by linear regression analysis.

Conclusions. A combination of hypertension and type 2 diabetes mellitus revealed a significant increase of GDF-15 levels in compare with patients with only hypertension or type 2 diabetes mellitus, which may be due to a greater response to oxidative stress and low-intensity systemic inflammation.

P-selectin mean level was higher in patients with grade 3 hypertension, which reflects a greater platelet activation as a part of the systemic inflammatory response.

Galectin-3 mean level was higher in patients with stage 3 hypertension compared with patients with stages 1 and 2 due to possibly more pronounced fibrosis progression.
\end{abstract}

Keywords: arterial hypertension, diabetes mellitus, markers of inflammation, GDF-15, P-selectin, Galectin-3.

DOI: $10.21303 / 2504-5679.2020 .001409$

\section{Introduction}

For decades, one of the most popular research fields in medicine is the impact of low-grade systemic inflammation in patients with arterial hypertension and type 2 diabetes mellitus, which leads to atherosclerosis and atherothrombosis. One of the major topics to be investigated in this field is finding the novel inflammatory markers, which will have greater prognostic significance in cardiovascular events and evaluation of treatment effectiveness.

The most common systemic inflammation markers in modern risk stratification practice are High-sensitivity C-reactive Protein (hs-CRP), Lipoprotein-associated phospholipase A2 (LpPLA2) and Myeloperoxidase (MPO) [1, 2]. Today, one of the most perspective markers are Growth Differentiation Factor 15 (GDF-15) [3, 4], P-selectin [5] and Galectin-3 [6, 7]. 
Despite of increasing numbers of studies of GDF-15, P-selectin and Galectin-3 in patients with acute coronary syndrome, there is still need to conduct researches in patients with AH and T2DM, which have high additional risk of cardiovascular events.

The aim of our study was to determine the base levels of GDF-15, P-selectin and Galectin-3 in blood plasma in patients with $\mathrm{AH}$ and T2DM and to assess their association with the diseases clinical course.

\section{Materials and methods}

A total of 121 patients who visited L. T. Malaya Therapy National Institute of the National Academy of Medical Sciences of Ukraine (Kharkiv, Ukraine) and 26-th City Outpatient Clinic (Kharkiv, Ukraine) from September 2017 to December 2019 were included in our study (60 female and 61 male, mean age $64.7 \pm 10.6$ years, with $\mathrm{AH}$ and/or T2DM). The study protocol was approved by the local Ethics Committee (The Committee on Ethics and Bioethics of Kharkiv National Medical University, protocol №5 of 12 September 2017). AH was diagnosed according to ESC recommendations [8], T2DM was diagnosed according to ADA recommendations [9].

Patients were divided into three groups: $1^{\text {st }}$ group with $\mathrm{AH}$ only (51 patient, mean age $64.82 \pm 10.17), 2^{\text {nd }}$ group with AH and T2DM (57 patients, mean age $\left.-64.71 \pm 11.51\right)$ and $3^{\text {rd }}$ group with T2DM only (13 patients, mean age $-63.77 \pm 9.63$; control group).

OBPM and ABPM carried out according to guidelines [8, 10].

GDF-15 test was performed using standard enzyme-linked immunosorbent assay kit (ELISA). The detection limitation was $16 \mathrm{pg} / \mathrm{mL}$ and a linear range from 35-4480 pg/mL (Human GDF15/MIC-1 Elisa, BioVendor, Czech Republic).

P-selectin test was performed using standard enzyme-linked immunosorbent assay kit (ELISA). The detection limitation was $0.20 \mathrm{ng} / \mathrm{mL}$ and a linear range from 0.8-267 ng/mL (Human sP-selectin Platinum ELISA, eBioscience, Bender MedSystems, Austria).

Galectin-3 test was performed using standard enzyme-linked immunosorbent assay kit (ELISA). The detection limitation was $0.29 \mathrm{ng} / \mathrm{mL}$ and a linear range from 0.47-30.0 ng/mL (Human Galectin-3 Platinum Elisa, eBioscience, Bender MedSystems, Austria).

Statistics were calculated using IBM SPSS (V 25, USA). Data are presented as mean value with standard deviation (mean \pm SD). Student's t-test, Mann-Whitney U test, Pearson or Spearman analysis, linear regression analysis and analysis of variance (ANOVA) were used to compare groups, dependent on the type and distribution of the data.

\section{Results}

Mean GDF-15 in blood plasma in all groups was $2944.59 \pm 2004.66 \mathrm{pg} / \mathrm{mL}$, Galectin-3 $12.65 \pm 5.35 \mathrm{ng} / \mathrm{mL}$, P-selectin $-110.14 \pm 37.08 \mathrm{ng} / \mathrm{mL}, \mathrm{hs}-\mathrm{CRP}-6.53 \pm 4.259 \mathrm{mg} / \mathrm{L}$.

Compared with AH without T2DM and T2DM only groups, AH with T2DM group had a higher level of GDF-15 (3824.71 $\pm 2474.41 ; 2130.48 \pm 874.52 ; 3039.04 \pm 1440.89 \mathrm{ng} / \mathrm{mL}, \mathrm{p}<0.05)$ (Table 1). AH without T2DM group had a higher mean P-selectin level than T2DM only group, but this difference did not reach confidence level.

Table 1

Mean inflammatory marker levels by group

\begin{tabular}{ccccc}
\hline \multirow{2}{*}{ Group } & \multicolumn{3}{c}{ Inflammatory markers } \\
\cline { 2 - 5 } & GDF-15 $(\mathbf{p g} / \mathbf{m L})$ & P-selectin $(\mathbf{n g} / \mathbf{m L})$ & Galectin-3 (ng/mL) & hs-CRP $(\mathbf{m g} / \mathbf{L})$ \\
\hline 1st group AH and T2DM (n=51) & $3824.71 \pm 2474.41^{*}$ & $114.09 \pm 36.06$ & $12.47 \pm 4.65$ & $4.85 \pm 3.46$ \\
2nd group AH only (n=57) & $2130.48 \pm 874.52$ & $106.61 \pm 37.93$ & $12.83 \pm 5.95$ & $5.92 \pm 4.44$ \\
3rd group T2DM only (n=13) & $3039.04 \pm 1440.89$ & $109.85 \pm 61.89$ & $14.50 \pm 9.67$ & $5.59 \pm 4.80$
\end{tabular}

Note: $*_{-}-p<0.05$ in comparison with other groups 
Gal-3 mean level was higher in T2DM only group compared to others, but statistical significance was not met $(12.47 \pm 4.65 ; 12.83 \pm 5.95$ and $14.50 \pm 9.67 \mathrm{ng} / \mathrm{mL}, \mathrm{p}>0.05)$. Mean hs-CRP level was insignificantly higher in AH and T2DM group compared to AH only group (4.85 \pm 3.46 ; $5.92 \pm 4.44 \mathrm{mg} / \mathrm{L}, \mathrm{p}>0.05)$.

In order to confirm significant difference between groups we performed ANOVA test (Table 2). GDF-15 had a significant difference between different groups. There were no statistically significant differences of other marker levels between groups.

Table 2

ANOVA test between different groups

\begin{tabular}{|c|c|c|c|c|c|c|}
\hline \multicolumn{2}{|c|}{ Groups } & \multirow{2}{*}{$\begin{array}{c}\text { Sum of Squares } \\
42.972\end{array}$} & \multirow{2}{*}{$\frac{\mathbf{d f}}{2}$} & \multirow{2}{*}{$\frac{\text { Mean Square }}{21.486}$} & \multirow{2}{*}{$\frac{\mathbf{F}}{0.606}$} & \multirow{2}{*}{$\frac{\text { Sig. }}{0.547}$} \\
\hline & Between Groups & & & & & \\
\hline \multirow[t]{3}{*}{ Galectin-3 } & Within Groups & 4185.592 & 118 & 35.471 & & \\
\hline & Total & 4228.564 & 120 & & & \\
\hline & Between Groups & 1506.830 & 2 & 753.415 & 0.464 & 0.630 \\
\hline \multirow[t]{3}{*}{ P-selectin } & Within Groups & 191571.438 & 118 & 1623.487 & & \\
\hline & Total & 193078.268 & 120 & & & \\
\hline & Between Groups & 37140951.671 & 2 & 18570475.836 & 10.422 & 0.000 \\
\hline \multirow[t]{3}{*}{ GDF-15 } & Within Groups & 138985104.188 & 78 & 1781860.310 & & \\
\hline & Total & 176126055.859 & 80 & & & \\
\hline & Between Groups & 78.527 & 2 & 39.264 & 2.234 & 0.122 \\
\hline \multirow[t]{2}{*}{ hs-CRP } & Within Groups & 632.739 & 36 & 17.576 & & \\
\hline & Total & 711.267 & 38 & & & \\
\hline
\end{tabular}

(Table 3).

We analysed inflammatory marker levels according to hypertension grade classification [8]

Table 3

Mean inflammatory marker levels by hypertension grade

\begin{tabular}{ccccc}
\hline \multirow{2}{*}{ Blood pressure } & \multicolumn{4}{c}{ Inflammatory markers } \\
\cline { 2 - 5 } & GDF-15 $(\mathbf{p g} / \mathbf{m L})$ & P-selectin $(\mathbf{n g} / \mathbf{m L})$ & Galectin-3 (ng/mL) & hs-CRP $(\mathbf{m g} / \mathbf{L})$ \\
\hline Normal BP $(\mathrm{n}=31)$ & $1892.06 \pm 788.23$ & $100.50 \pm 42.73$ & $13.44 \pm 6.50$ & $5.43 \pm 4.48$ \\
High normal BP (n=25) & $2346.26 \pm 1274.45$ & $111.64 \pm 35.71$ & $14.27 \pm 7.19$ & $9.41 \pm 4.24$ \\
Grade 1 hypertension (n=31) & $2942.03 \pm 1367.95$ & $111.50 \pm 45.81$ & $12.28 \pm 4.88$ & $6.86 \pm 3.95$ \\
Grade 2 hypertension (n=26) & $3303.33 \pm 1811.94$ & $111.10 \pm 35.60$ & $11.88 \pm 5.39$ & $4.85 \pm 3.20$ \\
Grade 3 hypertension (n=8) & $3542.43 \pm 3068.59^{* \dagger}$ & $133.95 \pm 28.13 *$ & $11.58 \pm 4.95$ & $4.81 \pm 4.10$
\end{tabular}

Note: $*-p<0.05$ in comparison with Normal BP; $\uparrow-p<0.05$ in compassion with Grade 1 hypertension group

Grade 3 hypertension group had a significantly higher level of GDF-15 compared with Grade $1 \& 2$ hypertension groups. P-selectin mean level was significantly higher in Grade 3 hypertension group GDF-15 compared with Grade $1 \& 2$ hypertension groups. There were no statistically significant differences in Galectin-3 levels between groups.

We analysed inflammatory marker levels according to hypertension stages classification [8] (Table 4). 
Table 4

Mean inflammatory marker levels by hypertension stage

\begin{tabular}{cccc}
\hline \multirow{2}{*}{$\begin{array}{c}\text { Hypertension disease } \\
\text { staging }\end{array}$} & \multicolumn{2}{c}{ Inflammatory markers } \\
\cline { 2 - 4 } Stage $1(\mathrm{n}=4)$ & 3278.45 & P-selectin $(\mathbf{n g} / \mathbf{m L})$ & Galectin-3 (ng/mL) \\
\hline htage $2(\mathrm{n}=18)$ & $2096.23 \pm 1613.24$ & $123.59 \pm 51.82$ & $11.25 \pm 3.40$ \\
Stage $3(\mathrm{n}=86)$ & $3083.02 \pm 2054.41$ & $107.91 \pm 33.31$ & $9.85 \pm 3.86$ \\
\end{tabular}

Note: $*-p<0.05$ in comparison with other groups

We observed no significant difference of GDF-15 and P-selectin levels between different stage groups. Stage 3 hypertension group had a significantly lower level of Galectin-3 compared with Stage $1 \& 2$ hypertension groups $(13.31 \pm 5.52 ; 11.25 \pm 3.40$ and $9.85 \pm 3.86 \mathrm{ng} / \mathrm{mL}$, $\mathrm{p}<0.05)$.

In order to confirm significant difference between different stages we performed ANOVA test (Table 5).

Table 5

ANOVA test between different hypertension stages

\begin{tabular}{|c|c|c|c|c|c|c|}
\hline \multicolumn{2}{|c|}{ Groups } & \multirow{2}{*}{$\begin{array}{c}\text { Sum of Squares } \\
186.401\end{array}$} & \multirow{2}{*}{$\frac{\mathbf{d f}}{2}$} & \multirow{2}{*}{$\begin{array}{c}\text { Mean Square } \\
93.201\end{array}$} & \multirow{2}{*}{$\begin{array}{c}\mathbf{F} \\
3.398\end{array}$} & \multirow{2}{*}{$\begin{array}{l}\text { Sig. } \\
0.037\end{array}$} \\
\hline & Between groups & & & & & \\
\hline \multirow[t]{3}{*}{ Galectin-3 } & Within groups & 2879.791 & 105 & 27.427 & & \\
\hline & Total & 3066.193 & 107 & & & \\
\hline & Between groups & 4300.701 & 2 & 2150.350 & 1.581 & 0.211 \\
\hline \multirow[t]{3}{*}{ P-selectin } & Within groups & 142809.566 & 105 & 1360.091 & & \\
\hline & Total & 147110.267 & 107 & & & \\
\hline & Between groups & 9273904.055 & 2 & 4636952.028 & 1.159 & 0.320 \\
\hline \multirow[t]{3}{*}{ GDF-15 } & Within groups & 296143273.551 & 74 & 4001936.129 & & \\
\hline & Total & 305417177.607 & 76 & & & \\
\hline & Between groups & 23.337 & 2 & 11.668 & 0.627 & 0.541 \\
\hline \multirow[t]{2}{*}{ hs-CRP } & Within groups & 520.873 & 28 & 18.603 & & \\
\hline & Total & 544.210 & 30 & & & \\
\hline
\end{tabular}

According to ANOVA test, Galectin-3 had a significant difference between different hypertension stages $(\mathrm{F}=3.398 ; \mathrm{p}=0.037)$. There were no statistically significant differences of other marker levels between groups.

We performed correlation and regression analysis due to different pathogenetic mechanisms of inflammatory markers. There were no significant correlations between P-selectin and GDF-15 $(\mathrm{r}=-0.114 \mathrm{p}=0.323)$, Galectin-3 and hs-CRP $(\mathrm{r}=0.199, \mathrm{p}=0.142)$ and P-selectin and hs-CRP $(\mathrm{r}=0.133$, $\mathrm{p}=0.476)$.We observed weak correlation between Galectin-3 and GDF-15 in blood plasma $(\mathrm{r}=0.260$ $\mathrm{p}=0.022$ ), which was confirmed by linear regression analysis (Fig. 1). 


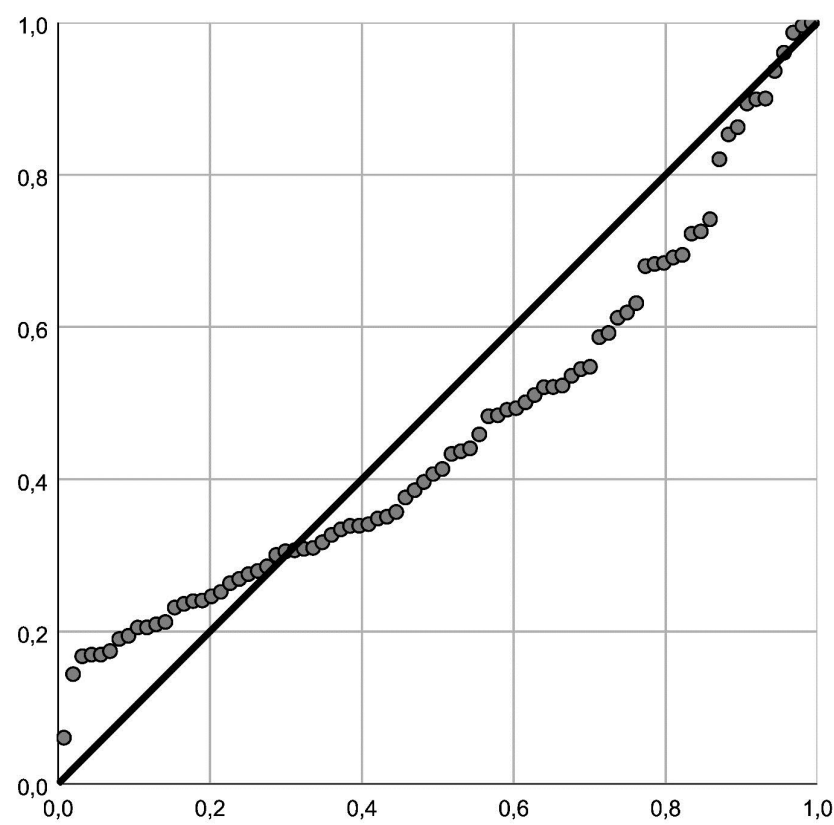

Fig. 1. Linear regression between Galectin-3 and GDF-15 plasma levels

\section{Discussion}

Correlation and regression analysis between inflammatory markers showed a weak relationship between galectin-3 and RDF-15 levels in the plasma and no significant correlations with P-selectin and standard systemic inflammation marker hs-CRP. We consider that our results create the prerequisites for searching an additional diagnostic and prognostic information.

In general, GDF-15 levels were significantly higher in patients with group of patients with hypertension and type 2 diabetes. Other studies have shown that GDF-15 activates atherosclerotic injury through interleukin-6 (IL-6) pro-inflammatory mechanisms [11, 12].

For increasing GDF-15 levels, it is necessary to activate a promoter with 2 p53 transcription factor binding sites, which is the fundamental response of cells to inflammation, oxidative stress, and oncogenic activation $[13,14]$. It is interesting to note that we detected maximum expression of GDF-15 in patients with hypertension and type 2 diabetes due to, probably, a greater damage to cells, which is associated with oxidative stress and low-intensity systemic inflammation. We also revealed a significant increase of P-selectin levels in patients with grade 3 hypertension. It is known that P-selectin, which is released on activated platelets and endothelial cells, can act as a counter ligand for GPIb $\alpha$ and, therefore, may mediate platelet adhesion and thrombus formation $[15,16]$. We suggest that the increase of P-selectin level reflects the activation of the platelet link of systemic inflammation in patients with grade 3 hypertension.

An increase of Galectin-3 level is primarily associated with the fibrosis progression as well as the development of heart failure [17, 18] and diabetes mellitus [19, 20]. The revealed increase in Galectin-3 in patients with stage 3 hypertension may be associated with the development of fibrosis and the initial stages of heart failure.

Study limitations. First, while the total sample size in our study was relatively large, the sample size of patients only with T2DM was small due to low frequency of patients without AH in this age.

Second, some plasma samples were stored more than 6 months.

On this basis, we conclude that the new inflammatory markers GDF-15, P-selectin and Galectin-3 reflect different pathogenetic mechanisms activation which are responsible for low-intensity systemic inflammation in patients with hypertension and type 2 diabetes and may provide various new diagnostic and prognostic information.

Further studies with larger sample sizes are necessary to confirm our findings. 


\section{Conclusions}

1. A combination of hypertension and type 2 diabetes mellitus revealed a significant increase of GDF-15 levels in compare with patients with only hypertension or type 2 diabetes mellitus $(3824.71 \pm 2474.41 ; 2130.48 \pm 874.52$ and $3039.04 \pm 1440.89 \mathrm{pg} / \mathrm{mL} ; \mathrm{p}<0.05)$, which may be due to a greater response to oxidative stress and low-intensity systemic inflammation.

2. P-selectin mean level was higher in patients with grade 3 hypertension (grade 3 $133.95 \pm 28.13$ Normal BP $-100.50 \pm 42.73 \mathrm{ng} / \mathrm{mL}$; $\mathrm{p}<0.05$ ), which reflects a greater platelet activation as a part of the systemic inflammatory response.

3. Galectin-3 mean level was higher in patients with stage 3 hypertension compared with patients with stages 1 and $2(13.31 \pm 5.52 ; 11.25 \pm 3.40$ and $9.85 \pm 3.86 \mathrm{ng} / \mathrm{mL} ; \mathrm{p}<0.05)$ due to possibly more pronounced fibrosis progression.

4. A weak correlation between GDF-15 and Galectin-3 was revealed $(r=0.260, p=0.022)$. There was no significant correlation between P-selectin and Galectin-3 as with the standard marker of inflammation hs-CRP which reflect the activation of various pathogenetic mechanisms of low-intensity systemic inflammation in patients with hypertension and type 2 diabetes. Therefore, this information creates the prerequisites for individualizing therapeutic goals.

\section{Conflict of interests}

The authors declare that they have no conflicts of interest.

\section{References}

[1] Ndrepepa, G. (2019). Myeloperoxidase - A bridge linking inflammation and oxidative stress with cardiovascular disease. Clinica Chimica Acta, 493, 36-51. doi: http://doi.org/10.1016/j.cca.2019.02.022

[2] Santos, H. O., Kones, R., Rumana, U., Earnest, C. P., Izidoro, L. F. M., Macedo, R. C. O. (2019). Lipoprotein(a): Current Evidence for a Physiologic Role and the Effects of Nutraceutical Strategies. Clinical Therapeutics, 41 (9), 1780-1797. doi: http:// doi.org/10.1016/j.clinthera.2019.06.002

[3] Krintus, M., Kozinski, M., Kubica, J., Sypniewska, G. (2014). Critical appraisal of inflammatory markers in cardiovascular risk stratification. Critical Reviews in Clinical Laboratory Sciences, 51 (5), 263-279. doi: http://doi.org/10.3109/10408363.20 14.913549

[4] Wesseling, M., Poel, J. H. C., Jager, S. C. A. (2020). Growth differentiation factor 15 in adverse cardiac remodelling: from biomarker to causal player. ESC Heart Failure, 7 (4), 1488-1501. doi: http://doi.org/10.1002/ehf2.12728

[5] Barale, C., Russo, I. (2020). Influence of Cardiometabolic Risk Factors on Platelet Function. International Journal of Molecular Sciences, 21 (2), 623. doi: http://doi.org/10.3390/ijms21020623

[6] Zhong, X., Qian, X., Chen, G., Song, X. (2019). The role of galectin-3 in heart failure and cardiovascular disease. Clinical and Experimental Pharmacology and Physiology, 46 (3), 197-203. doi: http://doi.org/10.1111/1440-1681.13048

[7] Di Gregoli, K., Somerville, M., Bianco, R., Thomas, A. C., Frankow, A., Newby, A. C. et. al. (2020). Galectin-3 Identifies a Subset of Macrophages With a Potential Beneficial Role in Atherosclerosis. Arteriosclerosis, Thrombosis, and Vascular Biology, 40 (6), 1491-1509. doi: http://doi.org/10.1161/atvbaha.120.314252

[8] Williams, B., Mancia, G., Spiering, W., Agabiti Rosei, E., Azizi, M., Burnier, M. et. al. (2018). 2018 ESC/ESH Guidelines for the management of arterial hypertension. European Heart Journal, 39 (33), 3021-3104. doi: http://oi.org/10.1093/eurheartj/ehy339

[9] Introduction: Standards of Medical Care in Diabetes - 2019. (2018). Diabetes Care, 42 (Supplement 1), S1-S2. doi: http:// doi.org/10.2337/dc19-sint01

[10] Whelton, P. K., Carey, R. M. (2018). The 2017 American College of Cardiology/American Heart Association Clinical Practice Guideline for High Blood Pressure in Adults. JAMA Cardiology, 3 (4), 352. doi: http://doi.org/10.1001/jamacardio.2018.0005

[11] Bonaterra, G. A., Zügel, S., Thogersen, J., Walter, S. A., Haberkorn, U., Strelau, J., Kinscherf, R. (2012). Growth Differentiation Factor-15 Deficiency Inhibits Atherosclerosis Progression by Regulating Interleukin-6-Dependent Inflammatory Response to Vascular Injury. Journal of the American Heart Association, 1 (6). doi: http://doi.org/10.1161/jaha.112.002550

[12] Wang, J., Wei, L., Yang, X., Zhong, J. (2019). Roles of Growth Differentiation Factor 15 in Atherosclerosis and Coronary Artery Disease. Journal of the American Heart Association, 8 (17). doi: http://doi.org/10.1161/jaha.119.012826

[13] Wollert, K. C., Kempf, T., Wallentin, L. (2017). Growth Differentiation Factor 15 as a Biomarker in Cardiovascular Disease. Clinical Chemistry, 63 (1), 140-151. doi: http://doi.org/10.1373/clinchem.2016.255174

[14] Corre, J., Hébraud, B., Bourin, P. (2013). Concise Review: Growth Differentiation Factor 15 in Pathology: A Clinical Role? STEM CELLS Translational Medicine, 2 (12), 946-952. doi: http://doi.org/10.5966/sctm.2013-0055 
[15] Prakash, P., Nayak, M. K., Chauhan, A. K. (2017). P-selectin can promote thrombus propagation independently of both von Willebrand factor and thrombospondin-1 in mice. Journal of Thrombosis and Haemostasis, 15 (2), 388-394. doi: http:// doi.org/10.1111/jth.13586

[16] Ivanov, I. I., Apta, B. H. R., Bonna, A. M., Harper, M. T. (2019). Platelet P-selectin triggers rapid surface exposure of tissue factor in monocytes. Scientific Reports, 9 (1). doi: http://doi.org/10.1038/s41598-019-49635-7

[17] Suthahar, N., Meijers, W. C., Silljé, H. H. W., Ho, J. E., Liu, F.-T., de Boer, R. A. (2018). Galectin-3 Activation and Inhibition in Heart Failure and Cardiovascular Disease: An Update. Theranostics, 8 (3), 593-609. doi: http://doi.org/10.7150/thno.22196

[18] Hogas, S., Bilha, S. C., Branisteanu, D., Hogas, M., Gaipov, A., Kanbay, M., Covic, A. (2017). Potential novel biomarkers of cardiovascular dysfunction and disease: cardiotrophin-1, adipokines and galectin-3. Archives of Medical Science, 4, 897-913. doi: http://doi.org/10.5114/aoms.2016.58664

[19] Berezin, A. E., Berezin, A. A. (2020). Circulating Cardiac Biomarkers in Diabetes Mellitus: A New Dawn for Risk Stratification - A Narrative Review. Diabetes Therapy, 11 (6), 1271-1291. doi: http://doi.org/10.1007/s13300-020-00835-9

[20] Lorenzo-Almorós, A., Pello, A., Aceña, Á., Martínez-Milla, J., González-Lorenzo, Ó., Tarín, N. et. al. (2020). Galectin-3 is Associated with Cardiovascular Events in Post-Acute Coronary Syndrome Patients with Type-2 Diabetes. Journal of Clinical Medicine, 9 (4), 1105. doi: http://doi.org/10.3390/jcm9041105

\title{
CURRENT TRENDS IN THE PREVALENCE OF FOOD HYPERSENSITIVITY IN CHILDREN OF THE KYIV REGION OF UKRAINE
}

\author{
Liudmyla Duda \\ Department of Pediatrics No. 1 \\ Shupyk National Medical Academy of Postgraduate Education \\ 9 Dorogozhytska str., Kyiv, Ukraine, 04112 \\ luda.duda@gmail.com
}

Abstract

The aim of the study. Due to the growing prevalence of food hypersensitivity worldwide and the number of dangerous food reactions, the aim was to determine the current prevalence of food hypersensitivity symptoms among children in the Kyiv region, Ukraine.

Methods. Total of 7106 children were surveyed: Group I (4 months - 5 years) had 1787 children, Group II (6-7 years) 2080 children, Group III (13-14 years) - 1909 children, Group IV (15-17 years) - 1330 children.

Results. The prevalence of food hypersensitivity among the surveyed children is $26.5 \%$ (95\% CI: $25.5-27.6)-$ this is 1888 children out of 7106. Highest prevalence of food hypersensitivity (FHS) is observed in the Group I, which is $32 \%$ (95\% CI: 29.8-34.2) - 571/1787, Groups II - 27.2 \% (95 \% CI: 25.7-29.8) - 566/2080, Groups III - $27.7 \%$ (95 \% CI: 14.7-18.0) - 529/1909, in the Group IV - 16.7 \% (95 \% CI: 25.3-29.2) - 222/1330). FHS in children is most often manifested by skin symptoms, followed by gastrointestinal manifestations, and acute urticaria/angioneurotic edema is at the third place. Respiratory manifestations possess $5 \%$ in the structure of FHS symptoms. An anaphylactic reaction was observed in 4 children out of 7106 respondents.

Conclusions. The prevalence of food hypersensitivity among Ukrainian children is high. There is an increase in the prevalence of urticaria/angioedema in preschool children.

Keywords: epidemiology, the prevalence of food hypersensitivity, food allergy, children, urticaria. 